\title{
Análise da germinação de cultivares de arroz submetidas a estresse por ácido acético
}

\author{
Germination analisys of rice cultivars under acetic acid stress \\ Mauricio Marini Kopp ${ }^{\mathrm{I} *}$ Viviane Kopp da Luz $^{\mathrm{I}}$ Luciano Carlos da Maia $^{\mathrm{I}}$ \\ Rogério Oliveira de Sousa ${ }^{\mathrm{II}}$ Fernando Irajá Félix de Carvalho ${ }^{\mathrm{I}}$ Antonio Costa de Oliveira ${ }^{\mathrm{I}}$
}

\begin{abstract}
O objetivo do trabalho foi avaliar a germinação de 12 genótipos de arroz submetidos ao estresse por ácido acético, composto fitotóxico produzido em solos com drenagem deficiente e alto teor de matéria orgânica. Foram realizados os testes de primeira contagem da germinação (PCG) e germinação $(G)$ dos genótipos submetidos às concentrações de $0 \mathrm{mM}, 4 \mathrm{mM}, 8 \mathrm{mM}$ e $12 \mathrm{mM}$ de ácido acético. As sementes de cada genótipo foram colocadas em papel germitest, os quais foram embebidos com as soluções-tratamento e acondicionados em sacos individuais. A germinação foi executada em câmara a $25^{\circ} \mathrm{C}$ e as contagens realizadas aos sete (PCG) e aos 14 dias $(G)$. O delineamento experimental utilizado foi fatorial inteiramente casualizado, com quatro repetições de 50 sementes por genótipo. As regressões estabelecidas para as variáveis revelaram três genótipos com estabilidade de germinação frente ao estresse por ácido acético.
\end{abstract}

Palavras-chave: estresse abiótico, ácidos orgânicos, Oryza sativa, fitotoxidez

\section{ABSTRACT}

The objective of this research was to evaluate the germination of 12 rice genotypes under acetic acid stress, a phytotoxic compound produced in low drainage soils with high organic matter content. The tests were conducted with the first count of germination (PCG) and germination $(G)$ of the genotypes subjected to $0 \mathrm{mM}, 4 \mathrm{mM}, 8 \mathrm{mM}$ and $12 \mathrm{mM}$ acetic acid concentrations. The seed of each genotype was placed in germitest paper that was embedded with treatment solutions and packaged in individual bags. The germination was performed at $25^{\circ} \mathrm{C}$ and the counts were carried out at 7 (PCG) and 14 days $(G)$. A factorial random block design was performed with four replications of 50 seeds per genotype. The regressions set for the variables showed three genotypes with germination stability under acetic acid stress.

Key words: abiotic stress, organic acids, Oryza sativa, phytotoxicity.

A região Sul do Brasil apresenta uma área de 6,8 milhões de hectares constituída por solos hidromórficos, representando $20 \%$ da área total do Estado do Rio Grande do Sul. Esses solos são cultivados predominantemente por arroz irrigado (GOMES \& MAGALHÃES JR, 2004). Como a cultura do arroz irrigado tem como característica principal a manutenção de uma lâmina de água sobre o solo durante a maior parte do seu desenvolvimento, o $\mathrm{O}_{2}$ presente é consumido e os microorganismos anaeróbios passam a atuar, produzindo elevada quantidade de produtos intermediários fitotóxicos por meio da fermentação da matéria orgânica presente no solo. Os principais produtos fitotóxicos produzidos são os ácidos orgânicos alifáticos de baixo peso molecular (acético, propiônico e butírico), que ocorrem na faixa de concentração de 0,1mMa 14mM(ANGELES et al., 2005) e relação de 6:3:1, respectivamente (BOHNEN et al., 2005). Os sistemas de plantio direto e cultivo mínimo de arroz irrigado prevêem a manutenção de resíduos vegetais sob a superfície do solo, ocorrendo maior

ICentro de Genômica e Fitomelhoramento, Universidade Federal de Pelotas (UFPel), Campus Universitário, s/nº, CP 354, 96010900, Pelotas, RS, Brasil. E-mail: marinikopp@gmail.com. *Autor para correspondência.

IDepartamento de Solos, UFPel, Pelotas, RS, Brasil. 
produção de ácidos orgânicos, que limitam o crescimento e a produtividade das plantas (JOHNSON et al., 2006).

A toxidez por ácidos orgânicos manifestase, nas fases iniciais de desenvolvimento do arroz, pela menor germinação (NEVES et al., 2006), pelo menor crescimento radicular, pelo menor peso e pela menor altura de plântulas (SOUSA \& BORTOLON, 2002). Em casos de toxidez mais severa, os prejuízos ao crescimento das plantas podem se refletir em outras fases, ocorrendo menor afilhamento, menor absorção de nutrientes e menor rendimento de grãos (CAMARGO et al., 2001). Como a maior produção de ácidos ocorre na fase inicial do plantio, os efeitos descritos podem estar mais intimamente relacionados à fase de germinação.

Com relação ao efeito dos diferentes ácidos orgânicos presentes no solo, quanto maior o tamanho da sua cadeia de carbonos do ácido maior sua fitotoxidez (RAO \& MIKKELSEN, 1977; ANGELES et al., 2005). KOPP et al. (2007a) demonstraram que $10 \mathrm{mM}$ dos ácidos acético, propiônico e butírico reduziram o crescimento radicular de arroz em torno de $44 \%, 70 \%$ e $77 \%$, respectivamente. Apesar de ser menos fitotóxico, a maior concentração de ácido acético no solo faz com que esse ácido apresente elevada importância na fitotoxidez total causada pelos ácidos orgânicos.

A acumulação de ácidos orgânicos no solo afeta diretamente as culturas, principalmente, pela inibição da respiração e pela degradação das membranas celulares (ARMSTRONG \& ARMSTRONG, 2001; ANGELES et al., 2005; JOHNSON et al., 2006).

A existência de variabilidade genética para tolerância a ácidos orgânicos no período vegetativo já foi identificada em aveia (KOPP et al., 2007b). No entanto, para arroz ainda não há descrição da variabilidade que poderá ser utilizada pelos programas de melhoramento. A incorporação de genes responsáveis pela manutenção da germinação sob estresse por ácidos orgânicos em cultivares elite poderá contribuir para a melhoria do estande de plantas na lavoura e, conseqüentemente, o incremento da área cultivada no sistema de semeadura direta de arroz irrigado, aumentando a produtividade e reduzindo os impactos ambientais do cultivo convencional e os custos de produção.

O objetivo deste trabalho foi avaliar a germinação de genótipos de arroz submetidos a estresse por ácido acético para utilização no melhoramento do estande de plantas, na lavoura de arroz irrigado sob sistema de semeadura direta e/ou cultivo mínimo.
O trabalho foi realizado no Laboratório de Duplo-haplóides e Hidroponia, do Centro de Genômica e Fitomelhoramento (CGF), da Faculdade de Agronomia Eliseu Maciel, da Universidade Federal de Pelotas (UFPel). Foram utilizados 12 genótipos de arroz do grupo índica e japônica e dos sistemas de cultivo irrigado e sequeiro, com diversas origens de lançamento.

$\mathrm{O}$ teste da germinação foi conduzido com 200 sementes, com quatro repetições de 50 sementes por tratamento, utilizando como substrato rolos de papel germitest previamente umedecidos com os tratamentos de ácido acético nas concentrações de $0 \mathrm{mM}, 4 \mathrm{mM}, 8 \mathrm{mM}$ e $12 \mathrm{mM}$. O pH foi ajustado para 4,7 com $\mathrm{HCl} 1 \mathrm{~N}$ ou $\mathrm{NaOH} 1 \mathrm{~N}$, pois o pH da solução em experimentos com ácidos orgânicos é variável e interfere na toxicidade dos ácidos (RAO \& MIKKELSEN, 1977; KOPP et al., 2007c). Foi utilizado um $\mathrm{pH}$ que mantivesse $50 \%$ do ácido acético na forma não-dissociada. Os rolos relativos a cada tratamento foram acondicionados em sacos plásticos lacrados para evitar contaminação entre os tratamentos, em virtude da volatilidade do ácido acético (CAMARGO et al., 2001). Todos os sacos contendo os genótipos e os respectivos tratamentos foram mantidos em germinador sob temperatura constante de $25^{\circ} \mathrm{C}$. As contagens foram realizadas no sétimo e no $14^{\circ}$ dia após semeadura (BRASIL, 1992).

O delineamento experimental utilizado foi inteiramente casualizado e as variáveis analisadas foram a primeira contagem da germinação (PCG) e a germinação $(G)$. Os dados relativos às variáveis mensuradas foram submetidos à análise descritiva e de variância após transformação por $\mathrm{x}^{2}$, conforme os resultados sugeridos pelo software utilizado (Statistical Analysis System - SAS). Os resultados permitem concluir que os genótipos apresentam respostas diferenciais em relação ao efeito crescente das concentrações de ácido acético, o que implica a necessidade de decomposição de seus efeitos simples.

Ao analisar o comportamento dos genótipos frente à primeira contagem da germinação (Figura 1), pode-se verificar que, para o genótipo Gose Yonkoku, existe uma estabilidade inicial no valor até a dose de $4 \mathrm{mM}$, seguida de uma redução significativa entre as doses de $4 \mathrm{mM}$ e $8 \mathrm{mM}$, estabilizando novamente seu desempenho em valores elevados de ácido acético. No genótipo Toride-1, observou-se que, para doses reduzidas de ácido, ocorre menor decréscimo na primeira contagem da germinação, com elevada redução nas doses mais elevadas principalmente a partir de $8 \mathrm{mM}$ do ácido. Para os genótipos BRS 7-Taim, Fanny, Yonaochi, Supremo-1, Gbegbbete, IAS-Formosa e IAC47, pode ser constatado que as reduções na primeira

Ciência Rural, v.38, n.9, dez, 2008. 

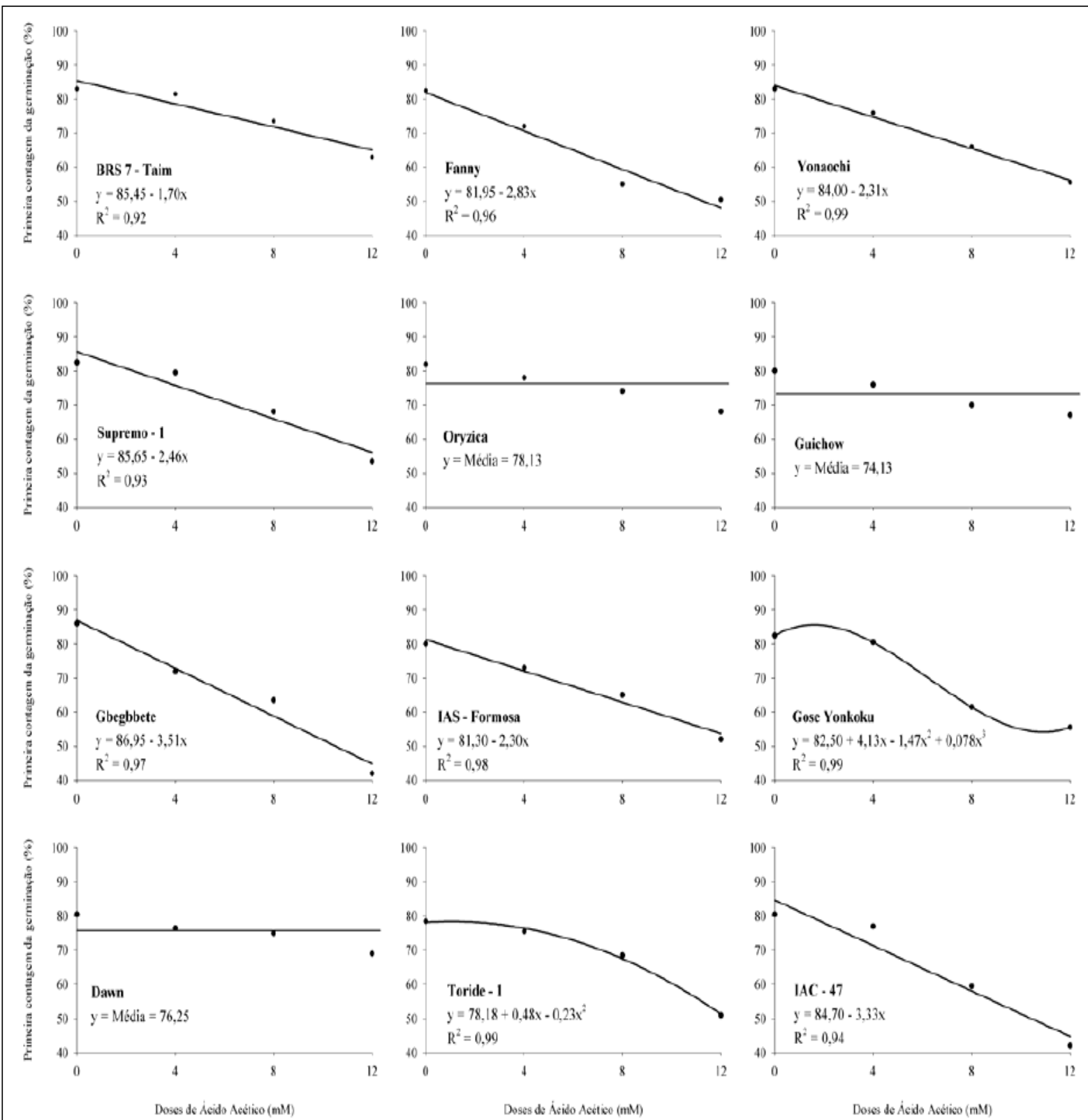

Figura 1 - Representação gráfica, ajuste das equações de regressão e coeficientes de determinação $\left(\mathrm{R}^{2}\right)$ da variável primeira contagem da germinação das 12 cultivares de arroz submetidas a quatro concentrações do ácido acético.

contagem da germinação foram constantes para as faixas de doses utilizadas no trabalho.

Para a variável germinação (Figura 2), o genótipo IAS-Formosa apresentou reduções elevadas entre as doses de $0 \mathrm{mM}$ e $4 \mathrm{mM}$ e entre $8 \mathrm{mM}$ e $12 \mathrm{mM}$. Já o genótipo Gose Yonkoku apresentou as maiores reduções entre as doses de $4 \mathrm{mM}$ e $8 \mathrm{mM}$. O genótipo Fanny apresentou elevada redução de germinação já em doses reduzidas até $8 \mathrm{mM}$, enquanto que o genótipo Toride-1 apresentou maior nível de redução de germinação em doses acima de $8 \mathrm{mM}$. Os genótipos
BRS 7-Taim, Yonaochi, Supremo-1, Gbegbbete e IAC47 apresentaram variação constante para as três doses utilizadas no experimento.

Como ainda não existe na literatura a descrição de níveis de redução para considerar um genótipo tolerante e não existem descrições de genótipos já classificados como tolerantes ou sensíveis para serem utilizados como testemunhas, foram considerados tolerantes os genótipos que se demonstraram insensíveis às concentrações de ácido acético utilizadas, ou seja, aqueles cujas médias não 

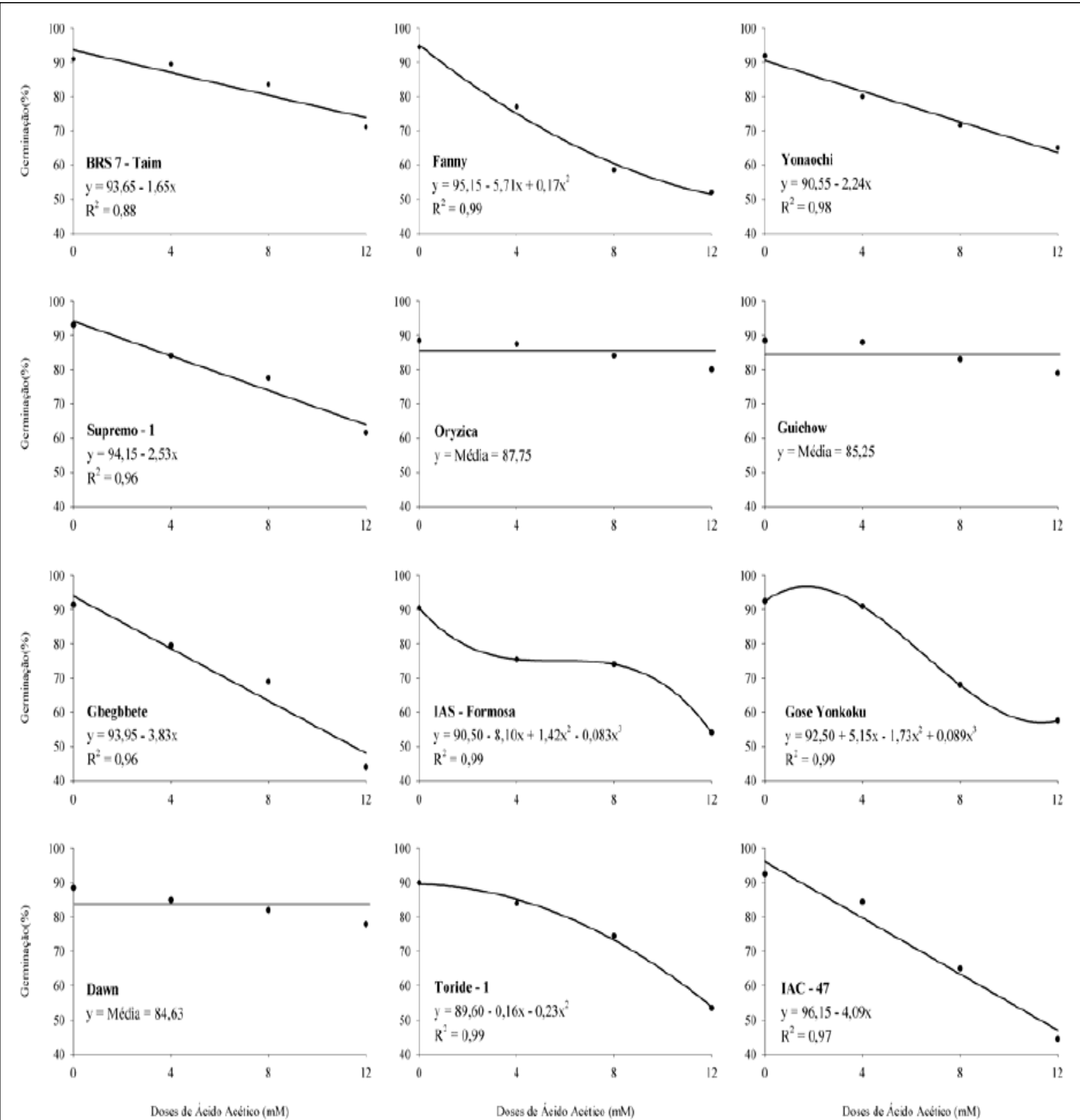

Figura 2 - Representação gráfica, ajuste das equações de regressão e coeficientes de determinação $\left(\mathrm{R}^{2}\right)$ da variável germinação das 12 cultivares de arroz submetidas a quatro concentrações do ácido acético.

foram alteradas significativamente com a elevação das doses utilizadas. Assim, os dados apresentados nas figuras 1 e 2 demonstram que os genótipos Oryzica, Guichow e Dawn foram classificados como tolerantes, pois não apresentaram variação significativa quando submetidos aos níveis de tratamento utilizados com médias de 78\%, 74\% e 76\% para PCG e 88\%, 85\% e 85\% para $\mathrm{G}$, respectivamente.

Os ácidos orgânicos em arroz causam principalmente degradação das membranas celulares e perda do conteúdo celular para o meio, de acordo com ARMSTRONG \&ARMSTRONG (2001). Esses mesmos pesquisadores relatam que plantas tolerantes devem possuir genes que conferem maior capacidade de formação de membranas celulares que tolerem estes ácidos. Assim, os genótipos descritos como de elevada capacidade de germinação sob estresse por ácido acético neste trabalho foram aqueles que se demonstraram insensíveis à toxicidade pelo ácido, pois apresentam maior possibilidade de possuírem genes 
responsáveis pela manutenção da capacidade celular em manter a germinação mediante a presença do elemento tóxico.

Ao analisar as figuras 1 e 2, é possível constatar que os genótipos tolerantes não necessariamente são também os genótipos com maior potencial em germinação, ou seja, eles são genótipos que apresentaram baixas características germinativas na dose controle $(0 \mathrm{mM})$, mas que possuem genes que mantém a viabilidade celular por meio da manutenção de suas membranas, garantindo a estabilidade germinativa frente à ação das doses do ácido. Além disso, os genótipos tolerantes são característicos de sistema de cultivo de irrigação por inundação. O processo de melhoramento desses genótipos nesse sistema provavelmente tenha ocorrido sob sistema de inundação, o que propiciou um ambiente com maiores concentrações de ácidos orgânicos e uma seleção indireta para o caráter pode ter sido decisiva para que um maior número de genótipos tolerantes fosse evidenciado dentro desse grupo de cultivares.

\section{REFERÊNCIAS}

ANGELES, O.R. et al. Soil solution sampling for organic acids in rice paddy soils. Soil Society American Journal, v.70, p.48-70, 2005.

ARMSTRONG, J.; ARMSTRONG, W. Rice and Phragmites: effects of organic acids on growth, root permeability, and radial oxygen loss to the rhizosphere. American Journal of Botany, v.88, p.1359-1370, 2001.

BOHNEN, H. et al. Ácidos orgânicos na solução de um gleissolo sob diferentes sistemas de cultivo com arroz irrigado. Revista Brasileira de Ciência do Solo, v.29, p.475-480, 2005.
BRASIL. Ministério da Agricultura e Reforma Agrária. Regras para análise de sementes. Brasília, 1992. 365p.

CAMARGO, F.A. et al. Aspectos fisiológicos e caracterização de toxidez a ácidos orgânicos voláteis em plantas. Ciência Rural, v.31, p.523-529, 2001

GOMES, A.S.; MAGALHÃES JR., A.M. Arroz irrigado no sul do Brasil. Brasília: Embrapa-Informação Tecnológica. 2004. 899p.

JOHNSON, S.E. et al. Faster anaerobic decomposition of a brittle straw rice mutant: implications for residue management. Soil Biology \& Biochemistry, v.38, p.1880-1892, 2006.

KOPP, M.M. et al. Efeito do pH da solução nutritiva na fitotoxidez causada por ácidos orgânicos em arroz. Magistra, v.19, p.40-46, 2007c.

KOPP, M.M. et al. Níveis críticos dos ácidos acético, propiônico e butírico para estudos de toxicidade em arroz em solução nutritiva. Acta Botanica Brasílica, v.21, p.147-154, 2007a.

KOPP, M.M. et al. Organic acid tolerance in M families of oat mutants. Crop Breeding and Applied Biotechnology, v.7, p.59-66, 2007b.

NEVES, L.A.S. et al. Influencia do ácido acético na qualidade fisiológica de sementes de arroz. Revista Brasileira de Agrociência, v.12, p.435-442, 2006.

RAO, D.N.; MIKKELSEN, D.S. Effect of acetic, propionic, and butyric acids on young rice seedlings growth. Agronomy Journal, v.69, p.923-928, 1977.

SOUSA, R.O.; BORTOLON, L. Crescimento radicular e da parte aérea do arroz (Oryza sativa L.) e absorção de nutrientes em solução nutritiva com diferentes concentrações de ácido acético. Revista Brasileira de Agrociência, v.8, p.231235, 2002. 